\title{
Carotenoid Distribution in Certain Naturally Occurring Algae and in some Artificially Induced Mutants of Chlorella pyrenoidosa
}

\author{
BY MARY BELLE ALLEN \\ Laboratory of Comparative Biology, Kaiser Foundation Research \\ Institute, Richmond, California, U.S.A. \\ T. W. GOODWIN* AND SAMARAVADI PHAGPOLNGARM \\ Department of Biochemistry, The University, Liverpool 3
}

(Received 28 January 1960)

\begin{abstract}
SUMMARY
The carotenoids of pure cultures of two members of the Class Chrysophyceae were examined; the main pigments in Ochromonas danica and Prymnesium paroum are fucoxanthin and $\beta$-carotene. The main carotenoids of Cyanidium caldarium are $\beta$-carotene and zeaxanthin; these observations support the view that this alga represents a transitional form between the cryptomonads and the green algae. The distribution of polyenes and carotenoids in a number of ultra-violet induced mutants of Chlorella pyrenoidosa is described.
\end{abstract}

\section{INTRODUCTION}

The general nature of the carotenoid pigments in many classes of algae is now reasonably well established (see Goodwin, 1958 $a$; 1959 $a, b ; 1960$ ). However, little is known of the carotenoids in the class Chrysophyceae, the only report available being that of Heilbron (1942) in which he reported $\beta$-carotene, lutein (3,3-dihydroxy$\alpha$-carotene) and fucoxanthin (structure unknown) in a mixed culture of Apistonema carteri, Thallochrysis litoralis and Gloeschrysis maritima. The reasons for this dearth of information have been: $(a)$ the difficulty in isolating pure strains of Chrysophyceae; $(b)$ the difficulty in devising culture media on which pure strains could be cultivated in bulk in the laboratory. These difficulties have now been overcome and the first part of this paper is concerned with the nature of the carotenoids present in pure strains of Ochromonas danica and Prymnesium parvum.

The second part of the paper is devoted to a study of the carotenoids in the unique alga Cyanidium caldarium; taxonomically this organism can be considered to be a green alga (Chlorophyceae), although it is known to produce phycocyanins and only chlorophyll $a$ (M. B. Allen, unpublished observations), which would suggest a close relationship with the Cyanophyceae (blue-green algae). However, as will be seen, its carotenoids are characteristic of neither the Chlorophyceae nor the Cyanophyceae.

\footnotetext{
* Present address: Department of Agricultural Biochemistry, University College of Wales,
} Aberystwyth. 
The final section of the paper deals with the carotenoid distribution in some ultraviolet induced mutants of Chlorella pyrenoidosa. Similar investigations on X-ray induced mutants of $C$. vulgaris have been carried out by Claes (1954).

Parallel studies on the distribution of chlorophylls in these algae will be reported elsewhere.

\section{METHODS}

\section{Organisms and methods of cultivation}

Cultures of Ochromonas danica and Prymnesium parvum were obtained from Dr J. J. A. McLaughlin. O. danica was grown in the defined medium shown in Table 1. P. parvum was grown in medium 'DC' of Provasoli, McLaughlin \& Droop (1957). Both organisms were grown at $18-20^{\circ}$ under approximately 300 f.c. of 'cool white' fluorescent light.

\section{Table 1. Defined medium for Ochromonas danica}

With either $0.5 \%$ glucose added or $5 \% \mathrm{CO}_{2}$ in air bubbled through the medium. The inorganic micronutrients are based on the $\mathbf{A} 4$ and $B 7$ solutions of Arnon (1938).

\begin{tabular}{|c|c|c|c|}
\hline \multicolumn{2}{|c|}{ Macronutrients } & \multicolumn{2}{|c|}{ Micronutrients } \\
\hline & (M) & & (mg./l.) \\
\hline $\begin{array}{l}\mathrm{MgSO}_{4} \\
\mathrm{KNO}_{3} \\
\left(\mathrm{NH}_{4}\right)_{2} \mathrm{SO}_{4} \\
\mathrm{CaCl}_{2} \\
\mathrm{KH}_{2} \mathrm{PO}_{4}\end{array}$ & $\begin{array}{l}0.001 \\
0.005 \\
0.005 \\
0.0005 \\
0.002\end{array}$ & $\begin{array}{l}\text { Thiamin } \\
\text { Biotin } \\
\text { Fe } \\
\text { Mn } \\
\text { B } \\
\text { Zn } \\
\text { Cu } \\
\text { Mo } \\
\text { V }\end{array}$ & $\begin{array}{l}10 \\
2 \\
4 \\
0 \cdot 5 \\
0 \cdot 5 \\
0 \cdot 05 \\
0 \cdot 02 \\
0.01 \\
0.01\end{array}$ \\
\hline
\end{tabular}

Mutants of Chlorella pyrenoidosa (Emerson strain; culture no. C-1. 1.10 in the Kaiser Foundation Research Institute culture collection) were obtained by ultraviolet irradiation with a Hanovia UV lamp. On plating the irradiated cultures, a large number of pigment mutants were found. With one exception (G 34) those investigated in the present work were originally of interest because their chlorophyll synthesis is disturbed so that they produce only chlorophyll $a$ (Allen, 1958). The mutants were grown in a medium containing: $\mathrm{MgSO}_{4}, 0.001 \mathrm{M} ; \mathrm{KNO}_{3}, 0.01 \mathrm{M}$; $\mathrm{NaCl}, 0.004 \mathrm{M} ; \mathrm{CaCl}_{2}, 0.0005 \mathrm{M} ; \mathrm{K}_{2} \mathrm{HPO}_{4}, 0.002 \mathrm{M}$; glucose $0.5 \%$; inorganic micronutrients shown in Table 1. Mutants G-41 and G-44 were grown in dim light (100 f.c.); mutant G-34 was grown in the dark, as it is photosensitive.

\section{Extraction, separation and identification of pigments}

The harvested cultures were freeze-dried, sealed under nitrogen and sent air mail from Berkeley to Liverpool. It was shown in a previous investigation that this transportation has no ill effects on the carotenoids in dried algal cells (Goodwin \& Gross, 1958). The dried organisms were weighed and then ground with acid-washed silver sand under acetone in a small mortar. The acetone extract was filtered through a sintered glass crucible $(P \times 4)$ and the process continued until the final acetone extract was colourless. The combined acetone extracts were then transferred to a 


\section{Carotenoids in algae}

separating funnel and an equal volume of diethyl ether (freshly distilled over reduced iron to remove peroxides) added; this was followed by adding water slowly until two layers formed. All the pigment was present in the upper ethereal layer, which was washed several times with successive small amounts of water until free from acetone. The ether was removed in vacuo and the residue was either chromatographed directly or saponified before chromatography. Except in cases where fucoxanthin was present, the extracts were saponified before chromatography; this removed chlorophylls and lipids which might interfere with the development of chromatograms. Fucoxanthin is the only known carotenoid which is destroyed by alkali, so when this pigment was present the saponification step was omitted.

Saponification of the extracts was carried out by the standard method in use in this laboratory (Goodwin, 1955). The extracts were generally dissolved directly in $2 \mathrm{ml}$. light petroleum (b.p. $40-60^{\circ}$ ) ready for chromatography. When the extracts contained large amounts of fucoxanthin or other polyhydroxylated carotenoids (which are insoluble in light petroleum) they were first dissolved in 2-5 drops of ether and then diluted to an appropriate volume with light petroleum. A number of different adsorbents have been used to separate the pigments. Icing sugar (confectioner's sugar, Tate and Lyle Ltd.) was ground in a mortar and activated by heating in an oven at $80^{\circ}$ for $6 \mathrm{hr}$. and then cooling in a desiccator; this adsorbent was used to separate xanthophylls. Alumina was used either activated (Grade ' $O$ ', Peter Spence and Sons Ltd., Widnes, Lancashire) or after deactivation according to the method of Goodwin \& Srisukh (1949). Activated alumina was used for separating the partly saturated polyene hydrocarbons phytoene and phytofluene from the more unsaturated compounds such as $\zeta$-carotene, neurosporene and $\beta$-carotene. Both phytoene and phytofluene are colourless; the latter was located on the column by its characteristic green fluorescence under ultraviolet irradiation. There is, however, no way easily to detect phytoene and it was obtained by collecting all the eluate running before phytofluene in $10 \mathrm{ml}$. fractions and bulking those fractions which exhibited the characteristic absorption peak of phytoene at $286 \mathrm{~m} \mu$ (Goodwin, $1952 a, 1955)$. Deactivated alumina was used for the rapid separation of $\beta$-carotene from oxygen-containing carotenoids.

Zinc carbonate + celite $(4: 1, \mathrm{w} / \mathrm{w})$ was used extensively for the separation and purification of xanthophylls, and magnesium oxide + celite $(4: 1, w / w)$ for the purification of $\beta$-carotene. Both were activated by heating to $180^{\circ}$, and stored in the same way as icing sugar.

Alumina columns were prepared by using a slurry, whereas all other adsorbents were packed dry (Goodwin, 1955). The chromatograms were developed by the method of gradient elution. The solvent used in all cases was light petroleum $\left(40-60^{\circ}\right)$ containing progressively increasing amounts of acetone; the apparatus used was very similar to that described by Lederer \& Lederer (1957); the original solvent was light petroleum (b.p. 40-60 $)$ and the final solvent light petroleum containing $10 \%(v / v)$ acetone. Xanthophylls are separated much more clearly, with little tailing, when gradient elution is used.

The individual pigments were identified $(a)$ by their position on the adsorption column relative to other known pigments, $(b)$ by the shape of their absorption curves and the position of the absorption maxima in various solvents, $(c)$ by mixed chromatography with an authentic specimen (Goodwin, 1955). The quantitative 
determination of the various pigment fractions was carried out as described previously (Goodwin, 1955) using the $E_{1 \% \mathrm{~m}}^{\mathrm{m}}$. values for each pigment quoted by Goodwin (1955). When the $E_{1 \mathrm{~cm}}^{1 \%}$ value of a pigment was unknown, it was assumed to be the same as that of $\beta$-carotene, i.e. 2500.

Partition tests were also applied to the isolated pigments. To carry out these tests a solution of the pigment in light petroleum was shaken with an equal volume of 90 or $95 \%(\mathrm{v} / \mathrm{v})$ methanol in water in a small test tube (ignition tube). In both tests hydrocarbons remain in the upper layer (epiphase). When $95 \%$ methanol in water was the lower phase then all xanthophylls are hypophasic; with $90 \%$ methanol in water the xanthophylls containing one oxygen function remain with the hydrocarbons in the epiphase whilst the remaining xanthophylls are hypophasic (Goodwin, 1955).

The pigment fractions were examined spectrophotometrically by using either a Unicam SP. 500 or SP. 600 instrument.

\section{RESULTS}

Carotenoids in Ochromonas danica and Prymnesium parvum (Chrysophyceae)

Ochromonas danica. Preliminary tests indicated the presence of fucoxanthin, so the step involving saponification had to be omitted. On chromatography on icing sugar, three main carotenoids were obtained (Table 2; the chlorophyll bands were ignored). Fraction A, which passed straight through the column with only light petroleum as developer, was purified on deactivated alumina and its identity with $\beta$-carotene was confirmed by co-chromatography with an authentic crystalline specimen (synthetic); no separation was obtained. The general properties of fraction $\mathbf{B}$, which was developed with light petroleum containing $3 \%(\mathrm{v} / \mathrm{v})$ acetone, including its destruction by alkali, suggested that it was fucoxanthin. This was confirmed by comparing it with an authentic specimen isolated from Laminaria saccharina (Phaeophyceae). Both pigments had the same absorption spectrum and could not be separated on co-chromatography on either icing sugar or a $\mathrm{ZnCO}_{3}$ + celite mixture. Fraction $\mathrm{C}$ which was firmly adsorbed on the column and was present only in small amounts was not identified. Quantitative determinations of the pigment fractions (Table 2) showed that fucoxanthin was the predominating pigment and that the total amount of pigment present was more than that recorded for various Phaeophyceae (see Goodwin, 1952b).

Prymnesium parvum. The pigment distribution in this alga was very similar to that observed in Ochromonas danica, but minor differences did exist. Fraction A

Table 2. The carotenoids present in Ochromonas danica

Pigment extract chromatographed on icing sugar ; fractions listed in order of increasing adsorptive power.

$\begin{array}{clcccc}\text { Fraction } & \text { Description } & \begin{array}{c}\text { Absorption } \\ \text { maxima }(\mathbf{m} \mu) \\ \text { in light } \\ \text { petroleum }\end{array} & \text { Identification } & \begin{array}{c}\text { Concn. } \\ \text { (mg./g. } \\ \text { dry wt.) }\end{array} & \begin{array}{c}\text { \% of total } \\ \text { pigment }\end{array} \\ \text { A } & \text { Yellow } & \mathbf{4 4 8 , 4 7 5} & \beta \text {-Carotene } & \mathbf{0 \cdot 7 2 5} & \mathbf{1 7 \cdot 0} \\ \text { B } & \text { Orange } & \mathbf{4 4 8 , 4 7 5} & \text { Fucoxanthin } & \mathbf{3 \cdot 1 6 0} & \mathbf{7 3 \cdot 8} \\ \text { C } & \text { Deep yellow } & \mathbf{4 4 5} & \text { Unknown } & \mathbf{0 \cdot 3 9 5} & \mathbf{9 \cdot 2}\end{array}$


(Table 3) on purification on deactivated alumina separated into two zones; the lower yellow zone was shown to be $\beta$-carotene. The other zone was not unequivocally identified; it exhibited absorption maxima (light petroleum) at 424, 445 and $470 \mathrm{~m} \mu$ and was probably a $c i s$ isomer of $\beta$-carotene. Fraction $\mathrm{B}$ showed properties very similar to that of zeaxanthin except that its absorption maxima in light petroleum were slightly higher; however, on co-chromatography with an authentic specimen of zeaxanthin prepared from maize the two fractions could be separated. Pigment B was therefore in all probability diatoxanthin, a pigment very similar to zeaxanthin found in diatoms by Strain, Manning \& Hardin (1944). Diatoxanthin according to Strain et al. has absorption maxima at slightly higher wavelengths than has zeaxanthin and, as just stated, this was also true for pigment B. A comparison of the absorption maxima of the three pigments is given in Table 4. Pigments $\mathrm{C}$ and $\mathrm{D}$ were present only in trace amounts and could not be unequivocally identified with any known pigment. Fraction $\mathrm{E}$ was proved to be fucoxanthin using the same criteria as those described for $O$. danica, and fraction $\mathbf{F}$ appeared to be the same pigment as fraction $\mathrm{C}$ ('Table 3 ) from $\boldsymbol{O}$. danica. The total pigment concentration was over twice as great as in $O$. danica, but fucoxanthin still represented about $75 \%$ of the total pigments present.

Table 3. The carotenoids present in Prymnesium parvum

Pigment extract chromatographed on icing sugar; fractions listed in order of increasing adsorptive power.

\begin{tabular}{|c|c|c|c|c|c|}
\hline Fraction & Description & $\begin{array}{c}\text { Absorption } \\
\text { maxima }(\mathrm{m} \mu) \\
\text { light } \\
\text { petroleum }\end{array}$ & Identification & $\begin{array}{l}\text { Conen. } \\
\text { (mg./g. } \\
\text { dry wt.) }\end{array}$ & $\begin{array}{c}\% \text { of } \\
\text { total } \\
\text { pigment }\end{array}$ \\
\hline $\mathbf{A}$ & Yellow & - & $\begin{array}{l}\beta \text {-carotene + a cis- } \\
\text { isomer }\end{array}$ & $0 \cdot 70$ & $7 \cdot 4$ \\
\hline $\mathbf{B}$ & Orange-yellow & 450,480 & Diatoxanthin & $0 \cdot 65$ & $6 \cdot 1$ \\
\hline $\mathbf{C}$ & Orange-yellow & $420,445-7$ & Unknown & 0.28 & $2 \cdot 7$ \\
\hline $\mathrm{D}$ & Yellow & 425,450 & Unknown & 0.52 & $4 \cdot 8$ \\
\hline $\mathbf{E}$ & Orange & 448,475 & Fucoxanthin & $7 \cdot 91$ & $74 \cdot 3$ \\
\hline \multirow[t]{2}{*}{$\mathbf{F}$} & Yellow & 445 & $\begin{array}{l}\text { Unknown-same as } \\
\text { fraction C (Table 1) }\end{array}$ & 0.51 & $4 \cdot 7$ \\
\hline & & & Total & $10 \cdot 57$ & \\
\hline
\end{tabular}

Table 4. A comparison of the absorption maxima $(\mathrm{m} \mu)$ of zeaxanthin, diatoxanthin and pigment $\boldsymbol{B}($ Table 2$)$

$\begin{array}{lcc} & \begin{array}{c}\text { Solvent. } \\ \text { Light petroleum } \\ \text { (b.p. 40-60) }\end{array} & \text { Ethanol } \\ & & 450,478 \\ \text { Zeaxanthin (ex maize; present work) } & 448,476-478 & 450,478 \\ \text { Diatoxanthin (Strain } \text { et al. 1944) } & - & 453,478, \\ \text { Pigment B } & 450,480 & 452,481\end{array}$

Carotenoids in Cyanidium caldarium

The carotenoids present in Cyanidium caldarium were found to be $\beta$-carotene, zeaxanthin and lutein, with $\beta$-carotene predominating (Table 5). $\beta$-Carotene was identified in the usual way, whilst the identity of zeaxanthin was confirmed by 
co-chromatography with authentic zeaxanthin on two adsorbents: icing sugar and $\mathrm{ZnCO}_{3}+$ celite $(4: 1)$; no separation was obtained in either case. Fraction $\mathrm{C}$ was similarly identified by comparison with an authentic specimen of lutein isolated from grass. The total pigment concentration is very much less than in the two members of Chrysophyceae examined.

Table 5. The carotenoids present in Cyanidium caldarium

Pigment extract chromatographed on icing sugar; fractions listed in order of increasing adsorptive power.

$\begin{array}{clcccc}\text { Fraction } & \text { Description } & \begin{array}{c}\text { Absorption } \\ \text { maxima }(\mathrm{m} \mu) \\ \text { light } \\ \text { petroleum }\end{array} & \text { Identification } & \begin{array}{c}\text { Conc. } \\ \text { (mg./g. dry } \\ \text { wt.) }\end{array} & \begin{array}{c}\% \text { of total } \\ \text { pigment }\end{array} \\ \text { A } & \text { Yellow } & \mathbf{4 4 8 , 4 7 3} & \beta \text {-Carotene } & \mathbf{0 . 2 2 0} & \mathbf{5 4 \cdot 4} \\ \text { B } & \text { Orange-yellow } & \mathbf{4 4 8 , 4 7 5} & \text { Zeaxanthin } & \mathbf{0 \cdot 1 2 9} & \mathbf{3 1 \cdot 8} \\ \text { C } & \text { Yellow } & \mathbf{4 4 3 , 4 7 2} & \text { Lutein } & \mathbf{0 \cdot 0 5 7} & \mathbf{1 3 \cdot 8} \\ & & & \text { Total } & \mathbf{0 \cdot 4 0 6} & \end{array}$

Carotenoids in mutants of Chlorella pyrenoidosa

Mutant G. 34. The saponified extracts of this mutant were colourless and thus no carotenoids were present. However, chromatography on activated alumina demonstrated the presence of a colourless polyene, very similar to phytoene. As this compound is neither coloured nor fluorescent, the chromatogram was developed with light petroleum containing $0 \cdot 2 \%(\mathrm{v} / \mathrm{v})$ acetone and the eluate collected every $10 \mathrm{ml}$. A material with an absorption spectrum identical in shape and position of phytoene was obtained. Its distribution in the fractions collected was determined and in order to confirm the identity of this polyene with phytoene, an authentic specimen of phytoene was prepared from carrots, mixed with an equal amount of the mutant polyene and chromatographed as just described. The distribution curves for authentic phytoene and for the mixture were identical with that for the unknown polyene. This clearly demonstrated the identity of the two substances. The concentration of phytoene in the mutant was $1.71 \mathrm{mg} / \mathrm{g}$. dry wt. which is of the same order as that for the total carotenoids in the wild strain of C.pyrenoidosa from which the mutant was derived (see Table 9).

Mutant G. 44. When the carotenoids of this mutant were chromatographed on icing sugar it was found that the greater part of the fraction passed rapidly through the column; that is, the main components were hydrocarbon in nature. Chromatography of this fraction on activated alumina yielded the fractions listed in Table 6. Fraction A 1 was identified as phytofluene by the position and shape of its absorption maxima, by its green fluorescence under ultraviolet irradiation and by its failure to separate from an authentic specimen of phytofluene (from carrots) on co-chromatography. Fraction A 2 was further purified on $\mathrm{MgO}$ + celite $(3: 1, \mathrm{w} / \mathrm{w})$ and the major fraction had the same absorption spectrum and adsorptive power as $\zeta$-carotene (Nash \& Zscheile, 1945), but complete conformation could not be obtained because no authentic specimen of $\zeta$-carotene was available. The minor component of fraction A 2 was shown to be $\beta$-carotene in the usual way. Fractions A 3 and A 4 contained traces of pigments with the same absorption spectrum as $\zeta$-carotene but which were more strongly adsorbed. They were not examined further but they may 
have been monohydroxy derivatives of $\zeta$-carotene. It is interesting that although phytofluene is present in the mutant, phytoene is absent.

The xanthophyll fraction (B) was removed from the icing sugar and rechromatographed on $\mathrm{ZnCO}_{3}+$ celite $(4: 1, \mathrm{w} / \mathrm{w})$ using gradient elution. Six fractions were obtained, the absorption spectra of which are recorded in Table 7. As the xanthophylls represented only about $15 \%$ of the total pigments and as each fraction was present in approximately equal amounts there was not sufficient material for detailed examination. However, it is highly likely that B 2 is lutein and that B 3 is a di- or poly-hydroxy derivative of $\zeta$-carotene or of a polyene with a chromophoric

Table 6. The hydrocarbon polyenes present in mutant G. 44 of Chlorella pyrenoidosa

Pigments separated on $\mathrm{MgO}+$ celite mixture; fractions listed in order of increasing adsorptive power.

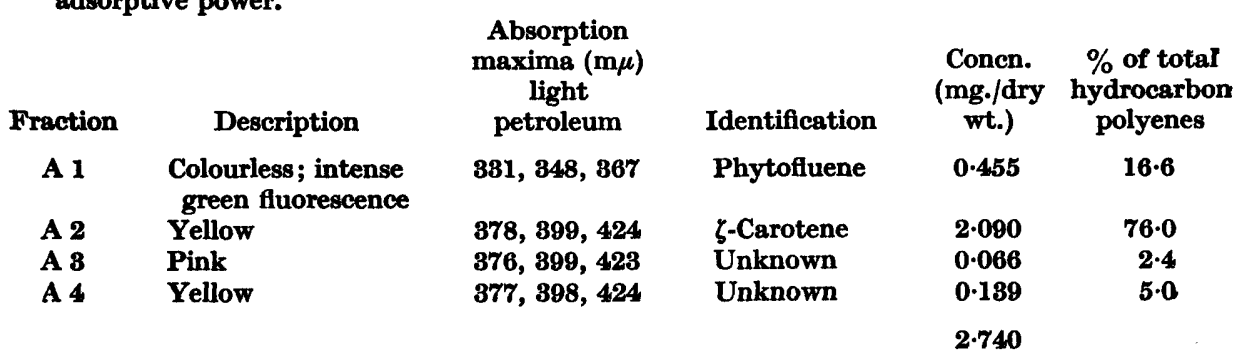

Table 7. The xanthophylls present in mutant G. 44 of

Chlorella pyrenoidosa

Pigments separated on $\mathrm{ZnCO}_{3}+$ celite $(4: 1, w / w)$ by means of gradient elution; fractions listed in order of increasing adsorptive power.

\begin{tabular}{|c|c|c|c|c|c|}
\hline Fraction & Description & $\begin{array}{c}\text { Absorption } \\
\text { maxima }(\mathbf{m} \mu) \\
\text { light } \\
\text { petroleum }\end{array}$ & Identification & $\begin{array}{l}\text { Concn. } \\
\text { (mg./g. dry } \\
\text { wt.) }\end{array}$ & $\begin{array}{l}\% \text { of total } \\
\text { carotenoids }\end{array}$ \\
\hline B 1 & Yellow & $374,395,418$ & Unknown & 0.008 & 0.2 \\
\hline B 2 & Orange & $421,448,470$ & Lutein & $0 \cdot 064$ & $\mathbf{2 \cdot 0}$ \\
\hline В 3 & Yellow & $374,397,423$ & $\begin{array}{l}\text { Hydroxy derivative of } \zeta- \\
\text { carotene or auroxanthin }\end{array}$ & $0 \cdot 180$ & $5 \cdot 5$ \\
\hline \multirow{3}{*}{$\begin{array}{l}\text { B 4 } \\
\text { B } 5\end{array}$} & Yellow & $397,415,438$ & Unknown & $0 \cdot 114$ & $\mathbf{3 \cdot 3}$ \\
\hline & Yellow & 432,460 & Unknown & 0.077 & $\mathbf{2 \cdot 3}$ \\
\hline & & & Total & $0 \cdot 443$ & $13 \cdot 8$ \\
\hline
\end{tabular}

system very similar to that of $\zeta$-carotene. This appears to be the first time that such pigments have been reported. $\mathrm{B} 1$, which is only present in traces, may be a hydroxylated derivative of $\zeta$-carotene or a cis isomer of the corresponding $\zeta$-carotene derivative (B 3). B 4 might be auroxanthin or a hydroxylated $\zeta$-carotene, but it was not investigated further, and $B$, which also could not be immediately identified, might be a degradation product.

Mutant G. 41. The pigments detected in this mutant are summarized in Table 8. The general distribution was very similar to that observed in the wild strain and the individual pigments were identified in the usual manner. There are, however, two 
minor differences: $(a) \alpha$-carotene is not present in the mutant; $(b)$ a mixture which could not be successfully separated and identified was different from the unknown fractions in the wild strains.

Table 8. The carotenoids present in mutant G. 41 of Chlorella pyrenoidosa

Xanthophylls separated on icing sugar; hydrocarbons on activated alumina; in both cases pigments were eluted with light petroleum containing increasing concentrations of acetone; pigments in order of increasing adsorptive power.

\begin{tabular}{|c|c|c|c|c|c|}
\hline Fraction & Description & $\begin{array}{c}\text { Absorption } \\
\text { maxima }(\mathbf{m} \mu) \\
\text { light } \\
\text { petroleum }\end{array}$ & Identification & $\begin{array}{l}\text { Conen. } \\
\text { (mg./g. dry } \\
\text { wt.) }\end{array}$ & $\begin{array}{l}\% \text { of total } \\
\text { carotenoids }\end{array}$ \\
\hline $\begin{array}{l}\text { A } \\
\text { B } 1 \\
\text { B } 2 \\
\text { B } 3 \\
\text { B 4 }\end{array}$ & $\begin{array}{l}\text { Yellow } \\
\text { Orange } \\
\text { Yellow } \\
\text { Yellow } \\
\text { Yellow }\end{array}$ & $\begin{array}{l}425,448,473 \\
443,472 \\
\text { Mixture } \\
418,440,468 \\
415,437,468\end{array}$ & $\begin{array}{l}\beta \text {-Carotene } \\
\text { Lutein } \\
\text { Unknown } \\
\text { Violaxanthin } \\
\text { Neoxanthin }\end{array}$ & $\begin{array}{l}0 \cdot 513 \\
0 \cdot 926 \\
0 \cdot 690 \\
0 \cdot 354 \\
0 \cdot 039\end{array}$ & $\begin{array}{r}20 \cdot 3 \\
36 \cdot 7 \\
26 \cdot 4 \\
14 \cdot 0 \\
1 \cdot 6\end{array}$ \\
\hline & & & Total & $2 \cdot 422$ & \\
\hline
\end{tabular}

Carotenoids present in Chlorella pyrenoidosa wild-type

In order to compare the pigments in the mutants with those of the parent strain the pigments present in Chlorella pyrenoidosa (wild-type) were examined; the results are summarized in Table 9. It will be seen that the main pigments are very similar to those reported in other green algae (Goodwin, 1952 b, 1955). It is interesting, however, that $\alpha$-carotene is present, although it is absent from most strains of C. vulgaris (Goodwin, 1955).

Table 9. The carotenoids present in Chlorella pyrenoidosa wild-type

Separation as described in Table 8 for mutant $\mathbf{G} 41$ of $C$. pyrenoidosa.

\begin{tabular}{|c|c|c|c|c|c|}
\hline Fraction & Description & $\begin{array}{c}\text { Absorption } \\
\text { maxima }(\mathrm{m} \mu) \\
\text { light } \\
\text { petroleum }\end{array}$ & Identification & $\begin{array}{l}\text { Concn. } \\
\text { (mg./g. } \\
\text { dry wt.) }\end{array}$ & $\begin{array}{l}\% \text { of total } \\
\text { carotenoids }\end{array}$ \\
\hline A 1 & Yellow & $420,445,472$ & $\alpha$-Carotene & 0.09 & $\mathbf{3 \cdot 6}$ \\
\hline A 2 & Orange-yellow & $425,448,473$ & $\beta$-Carotene & $\mathbf{0 \cdot 3 3}$ & $13 \cdot 5$ \\
\hline B 1 & Yellow & 442,470 & Lutein & $1 \cdot 11$ & $54 \cdot 8$ \\
\hline B 2 & Yellow & $415,438,466$ & Violaxanthin & $\mathbf{0 \cdot 2 2}$ & $9 \cdot 0$ \\
\hline B 3 & Pale yellow & $399,422,443$ & Unknown & $0 \cdot 10$ & $4 \cdot 2$ \\
\hline B 4 & Deep yellow & $415,440,467$ & Unknown & $0 \cdot 15$ & $6 \cdot 1$ \\
\hline \multirow[t]{2}{*}{$\mathbf{B ~} 5$} & Yellow & $417,435,463$ & Neoxanthin & $0 \cdot 21$ & $8 \cdot 8$ \\
\hline & . & & Total & $\mathbf{2 \cdot 2 1}$ & \\
\hline
\end{tabular}

\section{DISCUSSION}

The Chrysophyceae. The present work on pure cultures of Ochromonas danica and Prymnesium parvum confirms the earlier work of Heilbron (1942) who found $\beta$-carotene and fucoxanthin in a mixed culture of Apistonema carteri, Thallochrysis litoralis and Gloeschrysis maritima; it also demonstrates that fucoxanthin is by far the predominant pigment, representing some $75 \%$ of the total carotenoids present. 
Thus qualitatively the carotenoid distribution in these two examples of the class Chrysophyceae resembles very closely that found in the Phaeophyceae. The total amounts of pigment produced by the two algae vary considerably (Tables 2 and 3 ), but in any case the concentration in these two unicellular Chrysophyceae is much greater than that in the colonial Phaeophyceae for which values ranging from 0.36 to $1.9 \mathrm{mg}$./g. dry wt. have been recorded (Seybold \& Egle, 1938). Indeed P. parvum (10.57 mg./g. dry wt.) now becomes, to the best of our knowledge, the richest known algal source of carotenoids, the previous highest value being $c .7 \cdot 0 \mathrm{mg} / \mathrm{g}$. dry wt. recorded for Euglena gracilis v. bacillaris (Goodwin \& Jamikorn, 1954). The diatoms represent the other main class of algae which synthesize large amounts of fucoxanthin, and a relationship between the Chrysophyceae and this group is further indicated by the existence in $\boldsymbol{P}$. parvum of diatoxanthin, a pigment closely related to zeaxanthin and previously considered unique to diatoms (Goodwin, 1952b).

\section{Cyanidium caldarium}

Cyanidium caldarium is perhaps the most interesting of the recently examined algae. Taxonomically it can be considered a green alga, although its claim to be classed as a blue-green alga would appear strong on purely biochemical grounds when it is realized that it synthesizes phycocyanins and only chlorophyll $a$ (both characteristics of blue-green algae). The component carotenoids are, however, not characteristic of either the Cyanophyceae or the Chlorophyceae. They consist of a relatively large proportion of $\beta$-carotene ( $55 \%$ of the total pigments) with zeaxanthin as the main xanthophyll. The high proportion of $\beta$-carotene is reminiscent of the blue-green algae (Goodwin, 1958b), although Chlamydomonas reinhardii is also reported to contain comparative large amounts of $\beta$-carotene (Sager \& Zalokar 1958). The only other alga which is known to produce zeaxanthin or a closely related pigment, in comparatively large amounts, is Cryptomonas ovata, the first member of the Cryptophyceae to be examined in pure culture (Haxo \& Fork, 1959). The sporadic reports of zeaxanthin in some Phaeophyceae have been shown by Liaaen \& Sörensen (1956) to be due to the conversion of violaxanthin into zeaxanthin, brought about by drying the algae without all necessary precautions. The carotenoid distribution in $C$. caldarium is not incompatible with the view that it is a transitional form between the cryptomonads and the green algae, because it is possible that the cryptomonads represent a primitive flagellate groups from which the Chlorophyceae have developed. Quantitatively the amount of carotenoids synthesized is rather low (see Goodwin, 1952b).

\section{Mutant strains of Chlorella pyrenoidosa}

It is interesting to compare the pigments produced by various mutants of Chlorella pyrenoidosa with those in the mutant strains of $C$. vulgaris previously described by Claes (1954) (summarized in Table 10). In the first place C. pyrenoidosa mutants G. 34 and $C$. vulgaris mutant 5/871 are very similar in that they produce only phytoene; furthermore, in G. 34 the amounts produced are approximately the same as the total amount of carotenoid synthesized by the parent strains. Both are light-sensitive in the presence of oxygen. C. pyrenoidosa G. 44 and C. vulgaris 5/515 and $9 \mathrm{a}$ all accumulate phytofluene and $\zeta$-carotene, but unlike Claes's mutants, G. 44 does not synthesize phytoene. Furthermore, in G. 44 xanthophyll production was 
Table 10. Polyene distribution in mutants of Chlorella pyrenoidosa and $\mathrm{C}$. vulgaris $+=$ present; $-=$ absent.

\begin{tabular}{|c|c|c|c|c|c|c|c|c|c|}
\hline & \multicolumn{4}{|c|}{ C. pyrenoidosa } & \multicolumn{5}{|c|}{ C. vulgaris } \\
\hline & Wild-type* & G 84 & G 41 & G 44t & Wild-type & $5 / 871$ & $5 / 515$ & $5 / 520 \ddagger$ & $9 a \S$ \\
\hline Phytoene & - & + & - & - & - & + & + & + & + \\
\hline Phytofluene & - & - & - & + & - & - & + & + & + \\
\hline$\beta$-Carotene & + & - & + & - & + & - & - & - & - \\
\hline$\zeta$-Carotene & - & - & - & + & - & - & + & + & + \\
\hline Protetrahydrolycopene & - & - & - & - & - & - & - & + & - \\
\hline Prolycopene & - & - & - & - & - & - & - & + & - \\
\hline Lutein & + & - & + & + & + & - & - & - & + \\
\hline Violaxanthin & + & - & + & - & + & - & - & - & + \\
\hline Neoxanthin & + & - & + & - & + & - & - & - & + \\
\hline
\end{tabular}

* Also synthesizes $\alpha$-carotene.

$\dagger$ Also synthesizes a hydroxylated $\zeta$-carotene.

These pigments are formed in the dark; normal plastid pigments are produced in the light.

$\S$ An unidentified carotene is also present.

not completely inhibited (compare mutant 5/515), but it was decreased in amount and qualitatively altered (compare mutant $9 \mathrm{a}$ ); only about $20 \%$ of the total pigments were xanthophylls and they appeared to be mainly either hydroxylated derivatives of $\zeta$-carotene or compounds closely related to auroxanthin. It was not possible to decide between these alternatives. Our mutant G. 41 is interesting in that its ability to synthesize carotenoids has undergone little qualitative or quantitative change; its chlorophyll-synthesizing system has, however, been profoundly affected in that it does not synthesize chlorophyll $b$ (Allen, 1958).

We wish to thank Dr E. Burrows (Department of Botany, University of Liverpool) for kindly providing a specimen of Laminaria saccharina.

\section{REFERENCES}

Allen, M. B. (1958). Possible functions of chlorophyll $b$. Studies with green algae that lack chlorophyll $b$. The Photochemical Apparatus, its Structure and Function, Brookhaven Symposia in Biology, no. 11, p. 339.

ARNon, D. I. (1938). Microelements in culture-solution experiments with higher plants. Amer. J. Bot. 25, 322.

Claes, H. (1954). Biosynthese von Carotinoiden bei Chlorella. 1. Z. Naturf. $9 b, 322$.

Goodwin, T. W. (1952a). Studies in carotenogenesis. 3. Identification of the minor polyene components of the fungus Phycomyces blakesleeanus and a study of their synthesis under various cultural conditions. Biochem. J. 50, 550.

Goodwin, T. W. (1952b). The Comparative Biochemistry of the Carotenoids, p. 356. London: Chapman and Hall.

Goodwin, T. W. (1955). Carotenoids. In Handbook of Plant Analysis (ed. K. Paech \& M. V. Tracey), 3, 272. Heidelberg: Springer.

Goodwin, T. W. (1958a). Biosynthesis of vitamin A active carotenoids. Proc. 4th int. Congr. Biochem. XI, p. 54.

Goonwis, T. W. (1958b). The nature and distribution of carotenoids in some blue-green algae. J. gen. Microbiol. 17, 467.

Goodwin, T. W. $(1959 a)$. Some problems of carotenoid formation in photosynthetic tissues. Qual. Plant., 2, 162. 
Goodwrn, T. W. (1959b). The biosynthesis and functions of the carotenoid pigments. Advanc. Enzymol. 21, 296.

Goodwin, T. W. (1960). Carotenoids in Photosynthetic Tissues. In Handbook of Plant Physiology, 5, 394. Heidelberg: Springer.

Goopwin, T. W. \& Gross, J. A. (1958). Carotenoid distribution in bleached substrains of Euglena gracilis. J. Protozool. 5, 290.

Goodwin, T. W. \& JAMTKonN, M. (1954). Studies in carotenogenesis. Some observations on carotenoid synthesis in two varieties of Euglena. J. Protozool. 1, 216.

Goodwin, T. W. \& SRIsukn, S. (1949). The biochemistry of locusts. 1. The carotenoids of the integument of two locust species (Locusta migratoria migratorioides R. \& F. and Schistocerca gregaria Forsk.). Biochem. J. 45, 263.

HAxo, F. T. \& Fork, D. C. (1959). Photosynthetically active accessory pigments of cryptomonads. Nature, Lond. 184, 1061.

Heilbron, I. M. (1942). Aspects of algal chemistry. J. chem. Soc. p. 79.

LeDerer, E. \& Lederer, M. (1957). Chromatography, 2nd ed. p. 48. Amsterdam: Elsevier.

Lianen, S. \& Sörensen, N. A. (1956). Postmortal changes in the carotenoids of Fucus reticulosus. Proc. 2nd int. Congr. Searweed Research, p. 25.

NASH, H. A. (1945). Absorption spectrum of $\zeta$-carotene. Arch. Biochem. 7, 305.

Provasoli, L., McLaughun, J. J. A. \& Droop, M. E. (1957). The development of artificial media for marine algae. Arch. Mikrobiol. 25, 392.

Sager, R. \& Zalokar, M. (1958). Pigments and photosynthesis in a carotenoid deficient mutant of Chlamydomonas. Nature, Lond. 182, 98.

SeYboLd, A. \& Egre, K. (1938). Quantitative Untersuchungen über Chlorophyll und Carotinoide der Meeresalgen. J. veriss. Bot. 1, 50.

Strain, H. H., Manning, W. M. \& Hardin, G. (1944). Xanthophylls and carotenes of diatoms, brown algae, dinoflagellates and sea anemones. Biol. Bull., Woods Hole, 86, 170. 